$$
\text { الإعلام السياسي ... الدور_ التوجه_ الأثر }
$$

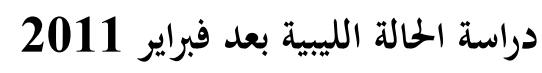

$$
\text { د. الممد جبريل بن طاهر }
$$

جامعة مصراتة/ كلية الفنون والإعلام

\title{
m.bentaher@media.misuratau.edu.iy
}

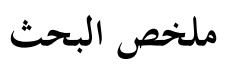

استخدم الباحث المنهج الوصفي التحليلي لدراسة الإعلام السياسي الليبي في فترة ما

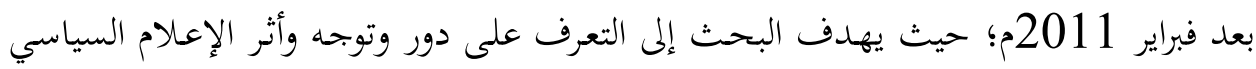

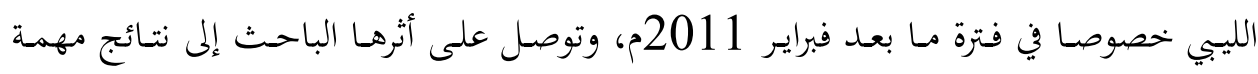

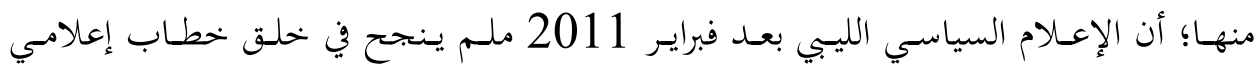
سياسي خاص به، وظل يماكي إعلام النظام السابق.

Research Summary

The researcher used the descriptive analytical method to study the Libyan political media in the post-February 2011 period. The aim of the research is to identify the role, direction and impact of the Libyan political media especially in the post-February 2011 period. February 2011 did not succeed in creating a political media speech of his own, and continued to mimic the media of the former regime.

$$
\text { الكلمات المفتاحية }
$$




\section{مقدمة البحث:}

يعد الإعلام السياسي الليبي موضوع بحـث جـدير بالاهتمـام لشغله حيزاكبيرا مـن مساحة الإعلام الليبي سواء كان ذلك في عهد القذافي أو بعده، حيث ركز الساسة الليبيون على بلى بلى لإعلى تمرير رسائلهم عبر وسائل الإعلام. ويسعى الباحث لمحاولة دراسة الإعلام السياسي وتوضيح دوره وتوجهه وأثره متخذا من

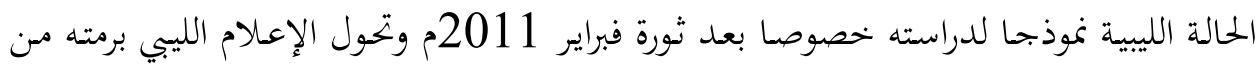
إعلام مؤدلج موجه إلى إعلام متعدد المشارب مفتوح دون مقص الرقيب. حيث سيقسم البحث إلى ستة مطالب، في الأول سيتعرض الباحث لتعريف الإعلام السياسي، ثم ثانيا سينتقل نحو إيضاح مزايا وصفات الإعلام السياسي، بعدها ثالثا سيدرس الإعلام السياسي الليبي قبل فبراير 2011، ورابعا سيتكلم عن الإعلام السياسي الليبي إبان فبراير 2011، وخامسا سيتعرض للإعلام السياسي الليبي بعد فبراير 2011 ليختتم بحثه فئه سادسا برؤية استشرافية للإعلام السياسي اللببي.

\section{مشكلة البحث:}

تتمحور مشكلة البحث حول دراسة دور وتوجه وأثر الإعلام السياسي الليبي في فترة

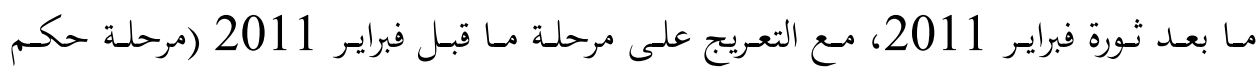
القذافي) وذلك لتأصيل البحث وللوقوف على إشكالية الإعلام السياسي اللبي و أدواره وكيفية

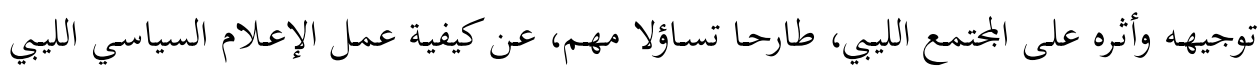

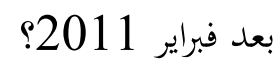

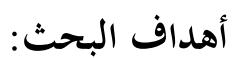

1- محاولـة الوقوف على أدوار وتوجهات وأثنر الإعـلام السياسي الليبي بعـد فبرايـر

2-رصد الظواهر السياسية وعلاقتها بالإعلام اللبي في محاولة لتحليلها. 3-المساهمة في تغطية النقص الشديد في المكتبة الإعلامية السياسية الليبية. 


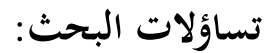

1-ما مدى دور وتوجه وأثر الخطاب السياسي الإعلامي الليبي بعد فبراير 2011 ؟

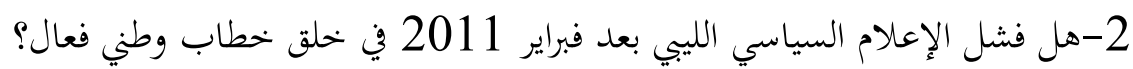

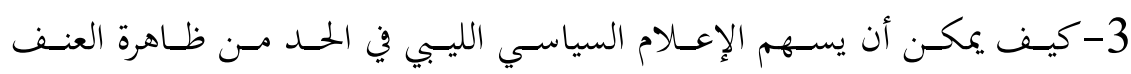

والإرهاب؟

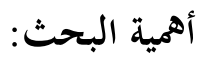

يعد الإعلام السياسي اللببي بعد فبراير 2011 مـ بين أكثر ألوان الإعلام انتشارا

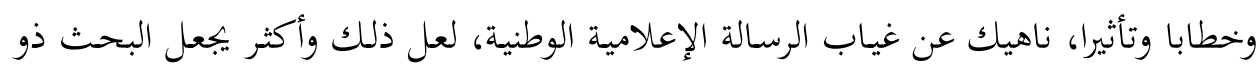
أهمية تدفع الباحث لدراسته في محاولة لتحليل الدور والتوجه والتأثير.

\section{منهج البحث:}

طبيعة البحث تفرض ضرورة استخدام المنهج الوصفي التحليلي.

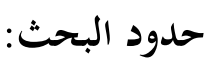

يدرس البحت الإعلام السياسي الليبي في فترة مـا بعد فبراير 2011 مع استعراض لفترة ما قبل فبراير.

$$
\text { أولا: تعريف الإعلام السياسي: }
$$

تتعدد تعريفات للإعلام السياسي حسب منطلقات الإعلاميين الأيديولوجية وسنعرض الإمي العاسي

$$
\text { لاحقا بعض تعريفات الإعلام السياسي ومنها: }
$$

الإعلام السياسي: هو حملة إخبارية منظمة هادفة تطلقها الدولة (المرسل) إلى الجمهور

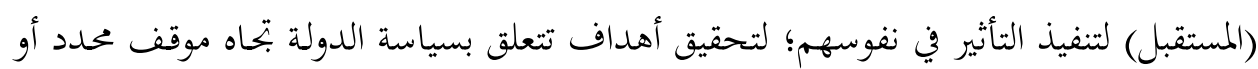

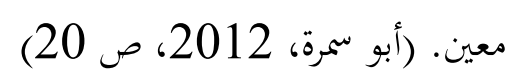

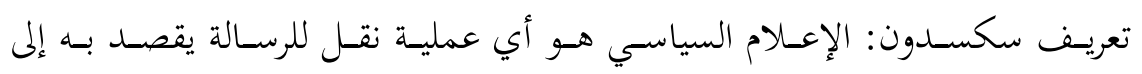

$$
\text { استخدام السلطة أو الترويح لها في البحتمع. }
$$


تعريف دينتون و وداورد: الإعلام السياسي هو المناقشة العامة حول السلطة ومصادر

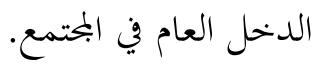
تعريف ميدو: والإعلام السياسي هو الرموز والرسائل المتبادلة المتأثرة بالنظام السياسي والمؤثرة فيه.

تعريف مانكير براين: الإعلام السياسي هو إعلام هادف يتعلق بالسياسة. تعريف كارل دويتش: الإعلام السياسي هو عصب العملية السياسية، فإذا كان الإعلام فاعلا قلل احتمالات الخطأ في اتخاذ القرارات التي هي قمة وغاية العمل السياسي. (عبدالفتاح، (185-184 2016، صن (18) يتضح مما سبق أن الإعلام السياسي هو نوع مـن أنواع الإعلام، ويمكن تعريفه بأنه الإعلام الذي يهتم بالسياسة والحكم، ويحاول عبره النظام السياسي بث رسالته بهدف التأثير في توني

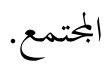
هناك عـدة مواضيع ومفـاهيم تتعلق بـالإعلام السياسي منها البيئة السياسية والدعاية

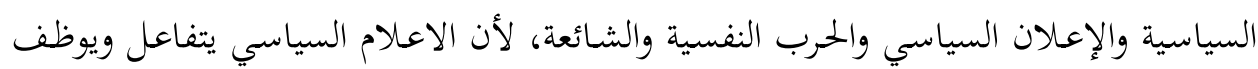

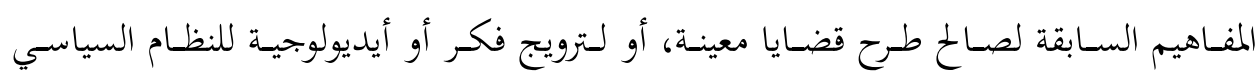
وحكومته.

\section{ثانيا: مزايا وصفات الإعلام السياسي:}

كما عرفنا الإعلام السياسي وقلنا إنه يهتم بنشر وترويج ما تريده الحكومات وإِ والساسة فإنه لابد أن يتمتع الإعلام السياسي بصفات ومزاياكي يكون إعلاما ناجحا، ومن تلك ولك المزايا أو الصفات ما يلي: 1-الواقعية: ينبغي على الإعلام السياسي نقل صورة الواقع دون تزييف أو مبالغة أو تهويل، مما يؤثر على الرأي العام ويوجهه نهو الطريق الخطأ.

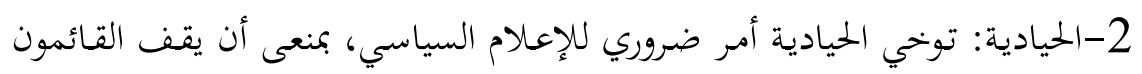

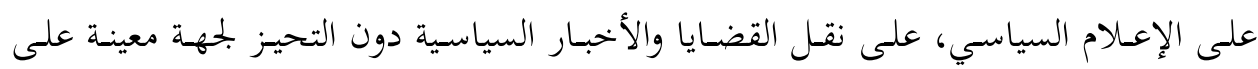




\section{الإعلام السياسي ... الدور_ التوجه_ الأثر}

مجلة كلية الآداب- العددالعاشر

حساب أخرى ودون تشويه الخبر أو الحدث، لأن ذلك يؤثر في آراء المتلقين ويوجهمه نحو اتخاذ قرارات خاطئة.

3-الموضوعية: تتجلى موضوعية الإعـام السياسي عند الإعلاميـين السياسيين الذين ينقلون

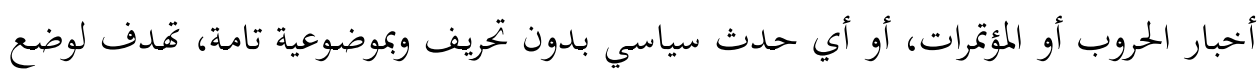
المتلقين في قلب الحدث، دون السعي للتأثير عليهم.

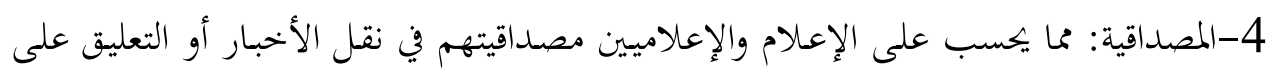

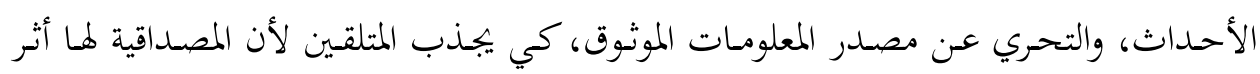
قوي وإيجابي لكسب ثقة الجمهور، وبناء عليها يتم تكوين الرأي العام الصادق والحقيقي.

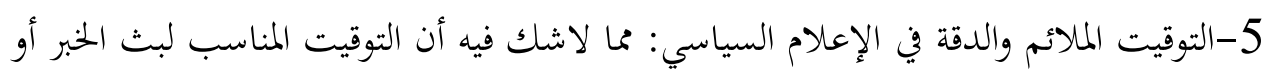

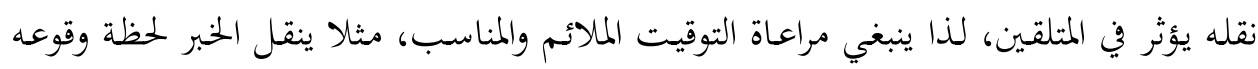

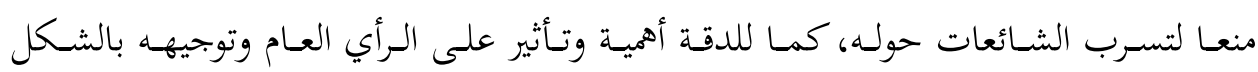
المطلوب.

6-النزاهـة واحسترام المواثيـق في الإعـلام السياسـي: نزاهـة الإعلاميـين بشـكل عـام والإعلاميـين السياسيين بشكل خاص أمر مهم، لأن فساد ذمم الإعلاميين يأتي على حساب مهنيتهم، كما

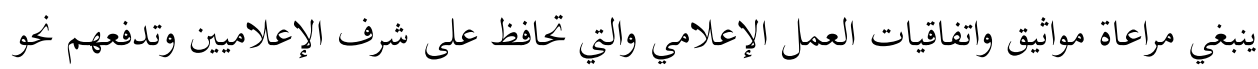
إعلام صادق وأخلاقي، حيث يؤثر ذلك كله على أراء الجمهور الذي سيكون صورة سيئة على إلى النظام السياسي في حالة انعدام النزاهة وعدم العمل وفق المواثيق الإعلامية. (أبو سمرة، 2012 إنداء

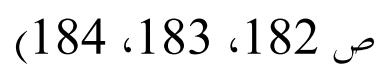

سيحاول الباحـث دراسة تلكك المزايـا والصفات ورصدها في الإعـلام السياسي الليبي

الذي شهد تحولات جذرية بعد ثورة فبراير 2011م. 


\section{ثالثا: الإعلام السياسي الليب قبل ثورة فبراير 2011م}

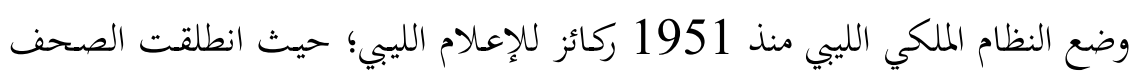
والمحلات والإذاعات في كبرى المدن الليبية، خلقت تلك المرحلة جيلا من الإعلاميين الليبيين ما انفكوا في انتقاد النظام الملكي وساسته . مـن مقر الإذاعة المسموعة بمدينة بنغازي أذيع بيـان الانقـاب، في الأول مـن سبتمبر

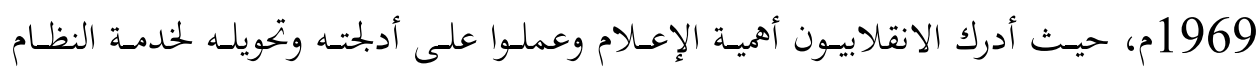
السياسي الحاكم ورموزه، كما ألغى بحلس قيادة الانقلاب معظم الدوريات الحكومية والمستقلة

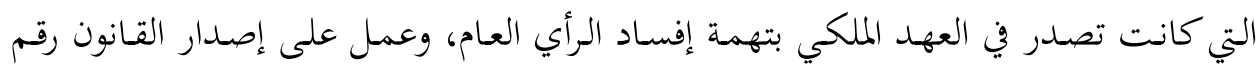

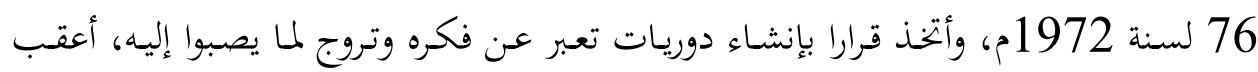

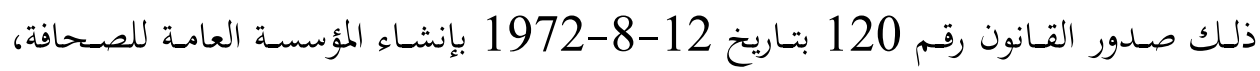
والقـانون رقم 60 بتـاريخ 25-12-1974 بإنشاء الشـركة العامـة للنشر والتوزيع والإعـالان.

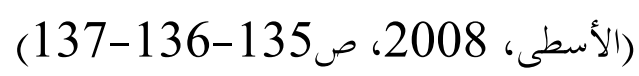
ما يهمنا هنا تتبع آلية الإعلام السياسي اللببي فقد سمى النظام السياسي حينها الإعلام الليبي (الإعلام الجماهيري) لإعطائه بعدا شعبيا سياسيا، تعود ملكيته وتخطيطه وإدارته ومضمونه

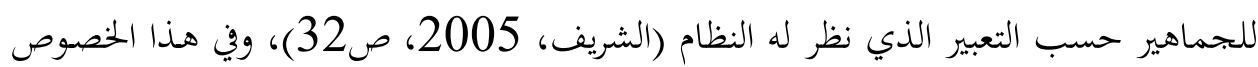
يقول معمر القذافي رأس النظام السياسي في كتابه الأخضر " الصحافة (الإعلام) وسيلة تعبير

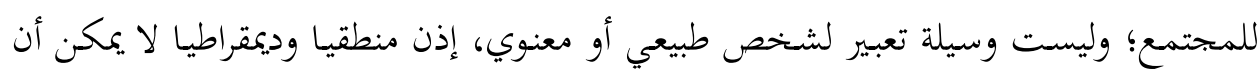

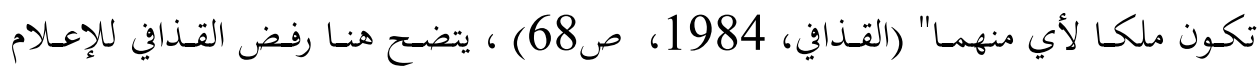
الخاص وتأكيده على ضرورة جعل الإعلام جماهيرياً شعبياً.

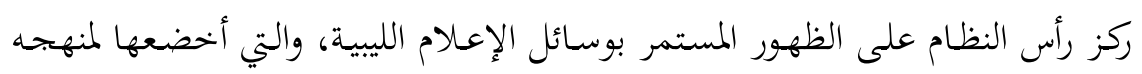

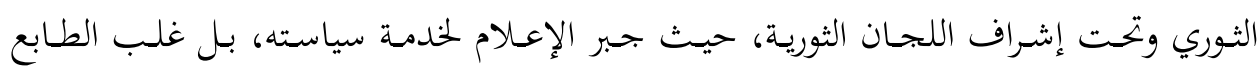
السياسي على المحالات الأخرى الاجتماعية والترفيهية والدينية ..إلخ، مثلا اطلق على التلفزيون

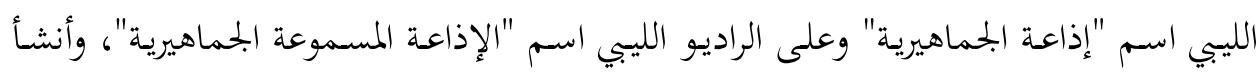


صحفاً يومية لخدمة النظام السياسي مثل "الفجر الجديد" " الزحف الأخضر" و "الجماهيرية" (الشريف، 2007، ص21-22-23-24-25)، تفنن الإعلام السياسي الليبي في تضليل

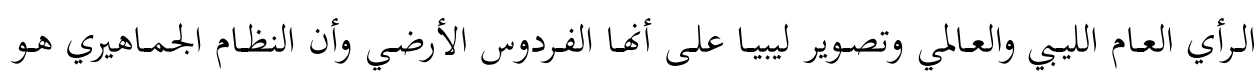
أفضل الأنظمة السياسية الديمقراطية في العالم.

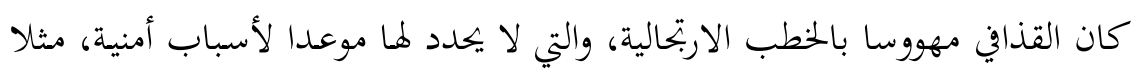
كان المواطن اللبي الجالس لمشاهدة مباراة كرة قدم أو مسلسل أو برنامج عبر إذاعة الجماهيرية

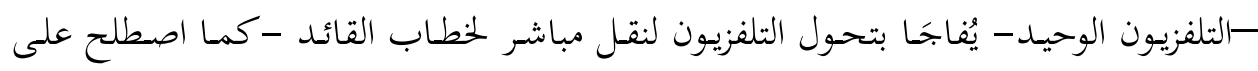
تسميته- والذي يمتد لساعات، أيضا عند انعقاد جلسات المؤتمرات الشعبية (السلطة التشريعية) يعمل التلفزيون والراديو على نقل وقائع الجلسات مع توقف تام لكل البرامج الإذاعية الأخرى.

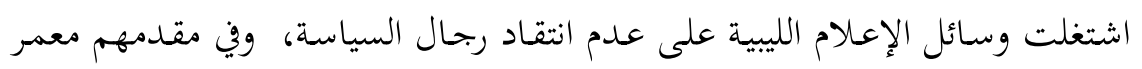
القذافي، بل ذهبت لانتقاد البرامج التنفيذية والتنبيه للأخطاء التي وقعت أثناء التنفيذ والتطبيق وفتـا لنظرية السلطة (المشابقة، 2014، ص134-135-136-137)، كماكرر القـذافي عبر وسائل الإعلام الليبية انتقاده (سلطة الشعب) واضعا اللوم على الشعب الليبي الذي أخطأ

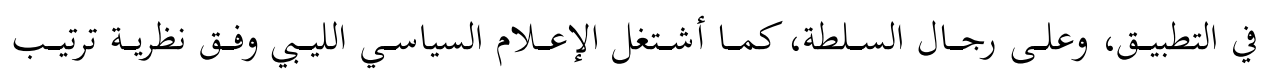
الأولويـات (الشـريف، 2015، ص86-87-88-89) على تقــيم كل مـا يتعلـق بالنظـام

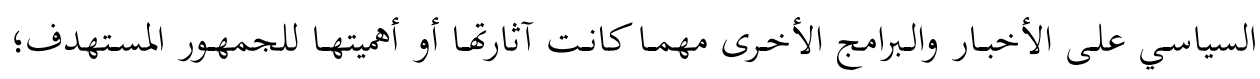

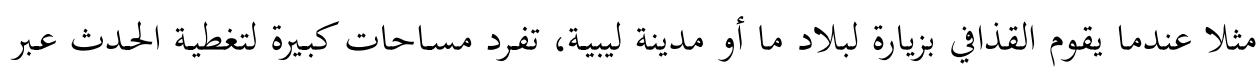
وسائل الإعلام الليبية، مع الإسهاب والإطراء والمدلح لشخص القذافي وإبحازات (ثورة الفـاتح العظيم) حسب تعبير وسائل الإعلام الليبية. حاول النظام السياسي الليبي التخفيف من حدة الخطاب المؤدلج عبر وسائل إعلامهـ وذلك لمسايرة التغيرات العالمية التي جاءت مع العولمة الإعلامية وأدواتما بنهاية القرن العشرين،

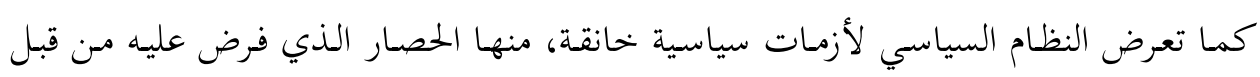

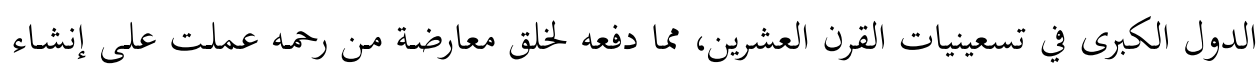


إعلام موازِ للإعلام الرسمي، تمثل في إصدار جرائد وافتتاح قناة مرئية وأخرى مسموعة، وإنشاء وكالة أنباء عبر مشروع ليبيا الغد بقيادة سيف الإسلام القذافي الذعي الذي حاول التأثير في الرأي

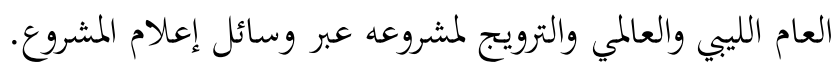

\section{رابعا: الإعلام السياسي الليبي أثناء ثورة فبراير 2011م:}

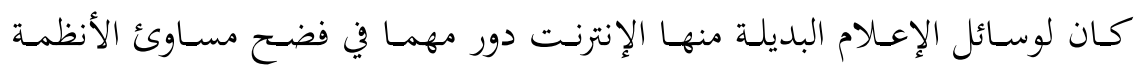
السياسـية العربيـة وتوعيـة المـواطن العـبي بمـا يـدور حوله، قابله شبه عجز الحكومـات العربيـة

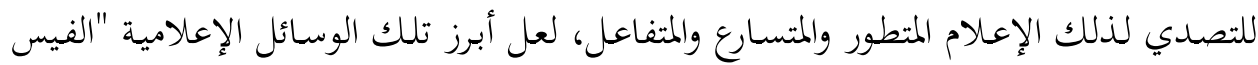

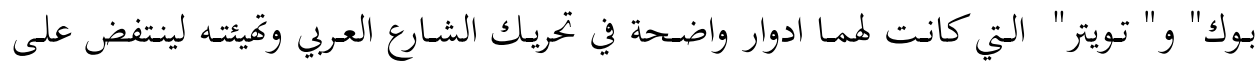
حكوماته فيما سمي بالربيع العربي، كانت ليبيا من ضمن الدول التي تأثرت بتلك الموجة.

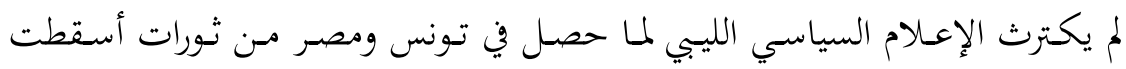

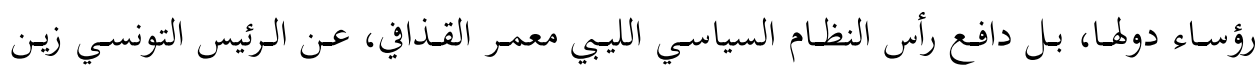

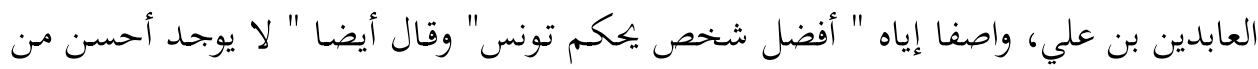

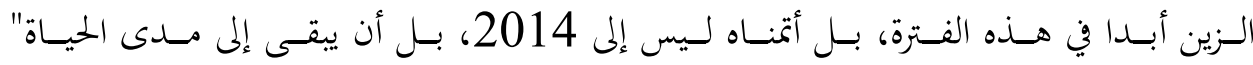
جساء ذلك في كلمـة wWw.youtube.com/watch?v=w7XK9UEsypw بثها التلفزيون الليبي الحكومي "إذاعة الجماهيريـة"؛ حيـث أبـدى القـذافي رفضه لإرادة الشعب التونسي في التغيير.

بدأت وسائل الإعلام الليبية في التعبئة الجماهيرية عندما تحرك الشارع الليبي في منتصف

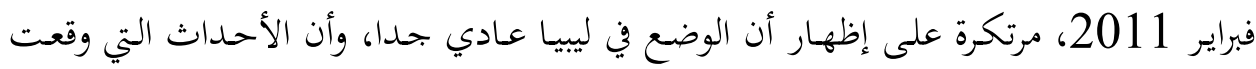

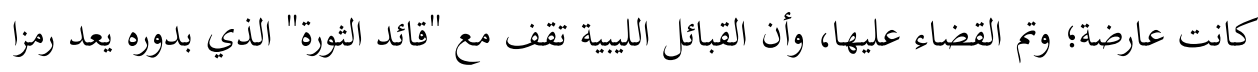

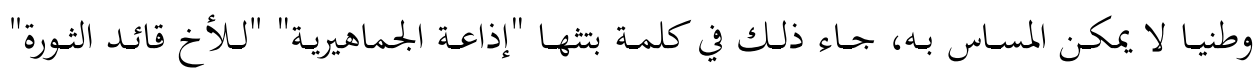
https://www.youtube.com/watch?v=pfCNfMUgbU4 كمااصطلح على تسميته بوسـائل الإعـام الليبية، هـدد فيها كل مـن يهاول المسـاس بـالأمن والسلم اللبي، سبقتها كلمة ابنه سيف الإسلام المحسوب على التيار الإصلاحي في ليبيا حيث توعد وهدد الشعب اللبي رافعا أصبعه في وجهه. 


\section{https://www.youtube.com/watch?v=1J_oECAgEto}

$$
\text { عبر إذاعة المحماهيرية كان يبث برنامج "عشم الوطن" }
$$
،https://www.youtube.com/watch?v=LpGGFIK5YrA

ما انفك طيلة مرحلة الأزمة على تلميع صورة النظام السياسي اللببي ورمزه القذافي، كما ذهب

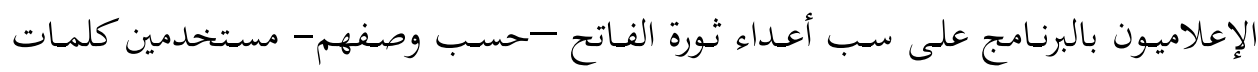

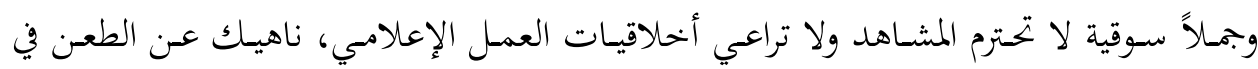

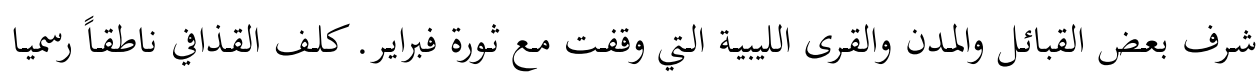

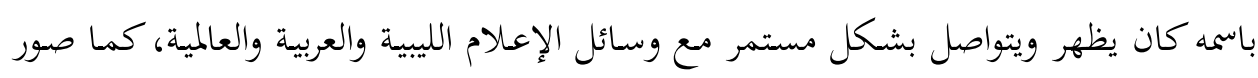

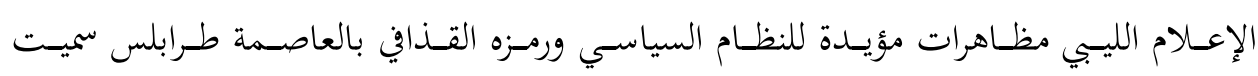
بالمظاهرات المليونية.

\section{خامسا: الإعلام السياسي اللبي بعد ثورة فبراير 2011م: فئل}

اعتبر مقتل القذافي في 20 أكتوبر 2011 فاية نظامه وبداية مرحلة جحديدة في في ليبيا

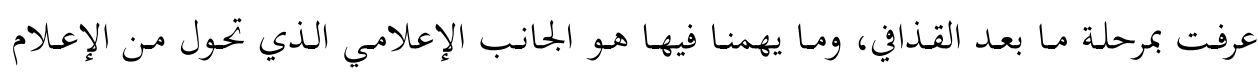

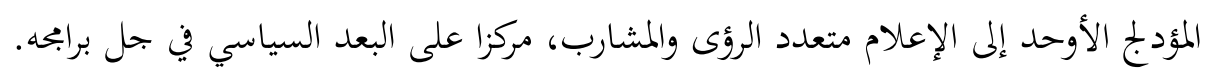

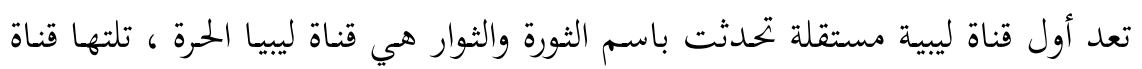

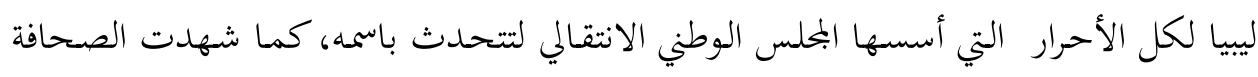

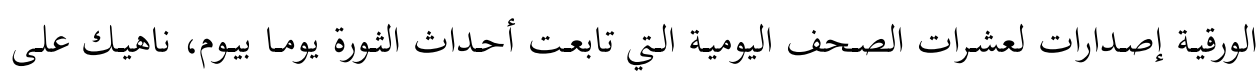

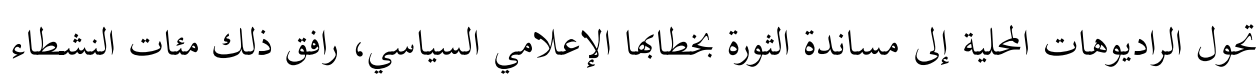
السياسيين والإعلاميين على صفحات وسائل التواصل الاجتماعي وعبر الفضائيات.

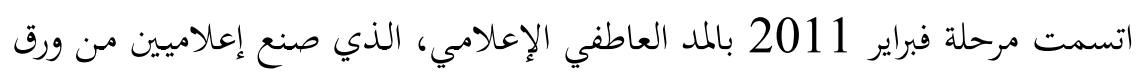

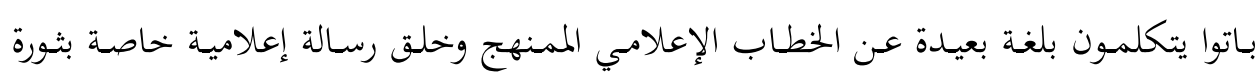

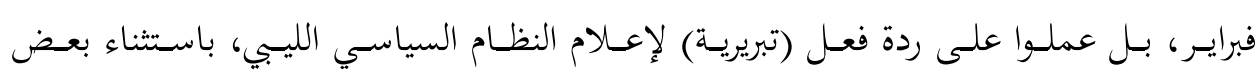

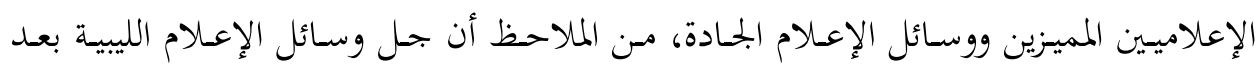


فبراير 2011 لم تستمر وواجهت عدة مشاكل فنية ومالية وإعلامية؛ تتعلق بمنهجية عملها في تلك المرحلة التي من المفترض أن تركز على بناء الدولة. تحولت جل وسائل إعلام فبراير نحو التكلم بلغة المناطقية والجهوية بعد انتهاء مرحلة التهلة

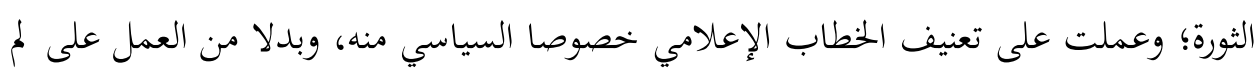

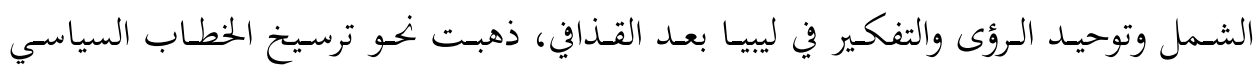

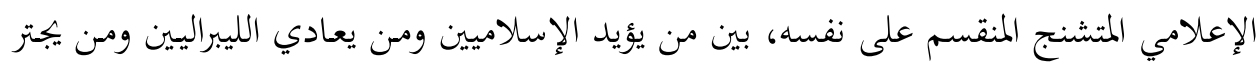

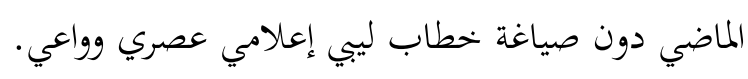
./http://lcfp.org.ly/report/hatespeech

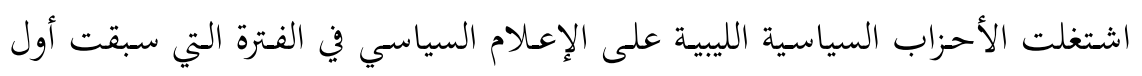

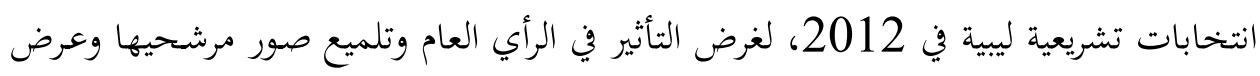

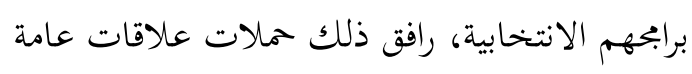
https://www.facebook.com/m.jibril.official.page/phot os/a.289061201162689.67926.278685185533624/3635016 50385310/?type=1\&theater

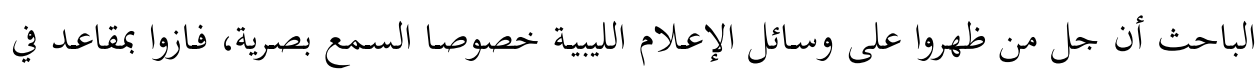
المؤتمر الوطني العام.

ركز القائمون على وسائل الإعلام الليبية بعد فبراير 2011 على تداول وبثث ونشر التار

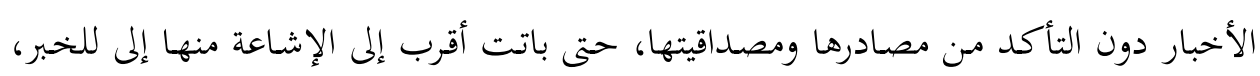

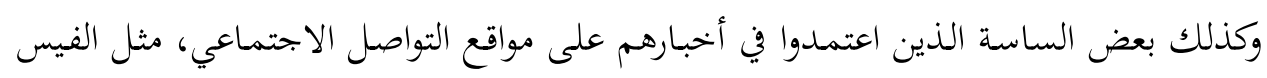

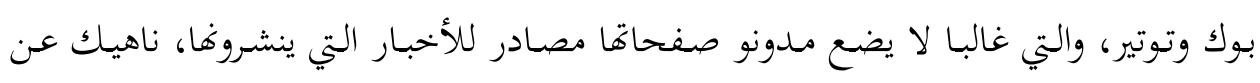

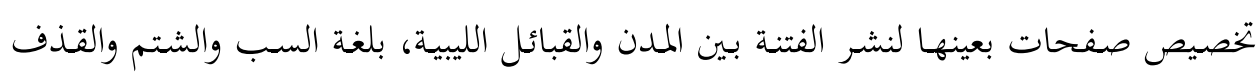

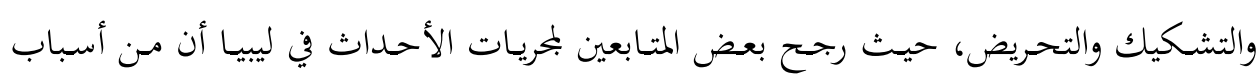

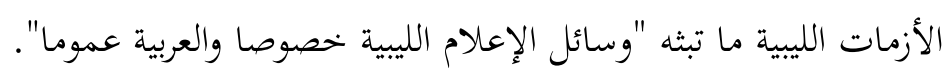




\section{سادسا: رؤية استشرافية للإعلام السياسي الليبي:}

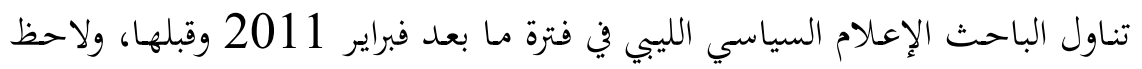

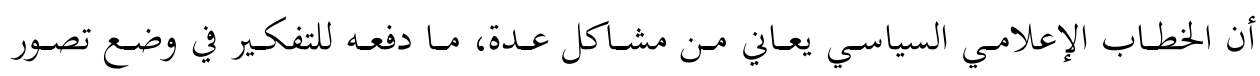
استشرافي للإعلام السياسي الليبي في النقاط التالية:

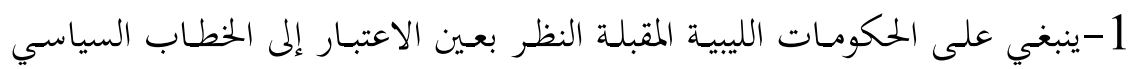

الليبي، باعتبارها مرحلة بناء بعد ثورة دموية مسلحة سادها خطاب إعلامي سياسي معنف،

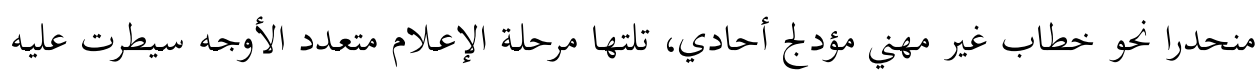
لغة عاطفية.

2- ينبغي على رجال السلطة الليبيون العمل على تأسيس خطاب إعلامي سياسي

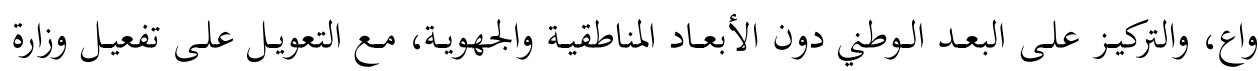
الإعلام للعمل على رقابة وسائل الإعلام الليبية وخطاباتما وسياساتما.

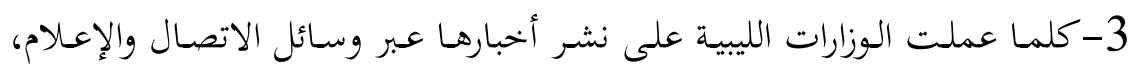

قابل ذلك انحصار مساحة انتشار الشائعة، التي باتت توجه وتؤثر في الرأي العام الليبي خصوصا تلك الأخبار ذات الطابع السياسي.

4-تقع على الحكومات الليبية المقبلة مهمة ثقيلة، تتعلق بكيفية العمل على توعية

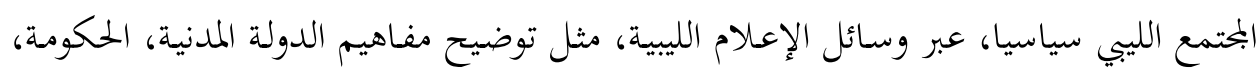

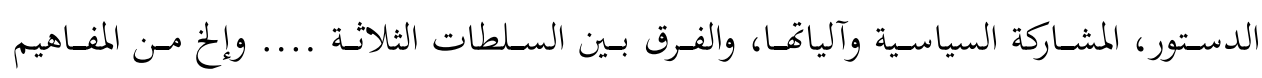

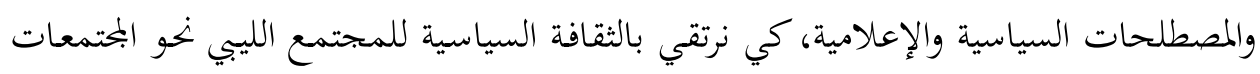
المتقدمة.

5-العمل على إصدار قانون ينظم العمل الإعلامي اللبي، خصوصا الشق السياسي

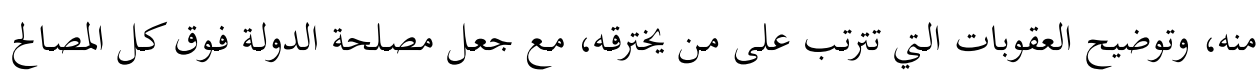
المناطيقة والجههوية الضيقة، وبحريم خطاب العنف والكراهية. 


\section{الخاتمة}

خلص الباحث إلى أن الإعلام السياسي الليبي قبل فبراير 2011 كان يقتات على

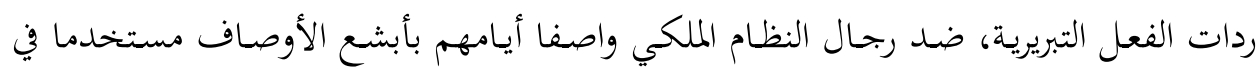

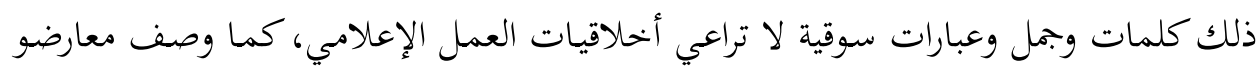
النظام (بالكاب الضالة) وعملاء الامبريالية والرجعية المتعفنة، ناهيك عن توظيف شعراء وفنانين

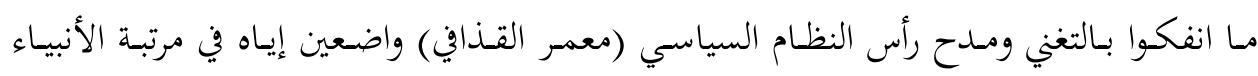
والرسل. كما لاحظ الباحث أن الإعلام السياسي اللبي (إعلام النظام السياسي السابق) أثناء فبراير 2011 وبعـدها، لم يخرج مس شرنقة ردات الفعل واللغـة السوقية والاستعانة بإعلاميين بعيدين غير مهنيين، كما امتهن الكذب والتدجيل وتزييف الواقع، لتضليل الرأي العام الليبي

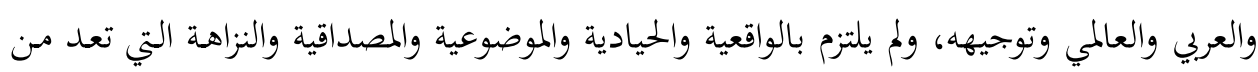

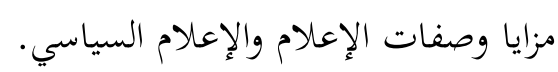

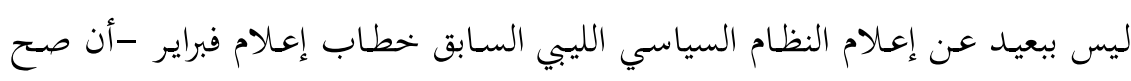

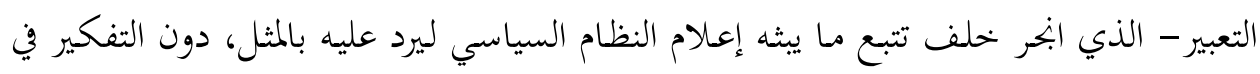

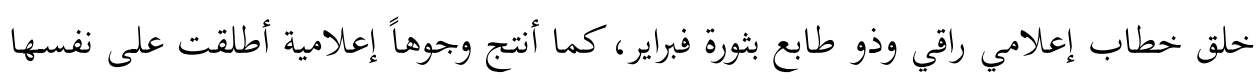

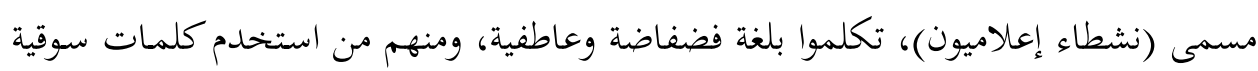
في خطاباته وتحليلاته للمشهد السياسي الليبي. خلص الباحث أيضا إلى أن وسائل الإعلام الليبية كانت ولازالت من الأسباب الرئيسة

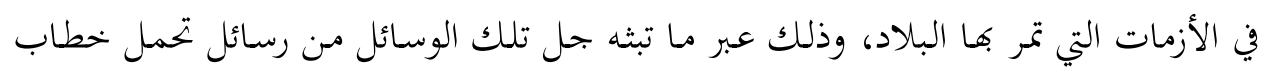
الكراهية والعنف والتحريض، ومنها من يرسخ خطاب المناطقية والجههوية والقبلية المقيتة. 


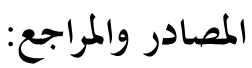

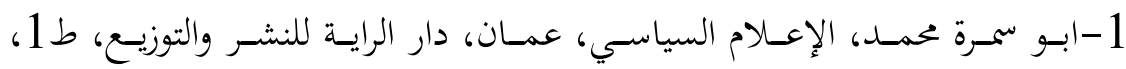

2-الأسـطى أسمـاء مصسطى، الصـحافة الليبيـة دارسـة حصـرية تحليليـة وببليوغرافيـا

1866-2003، سرت، بحلس الثقافة العام، ط1، 2008.

3-الشريف عابـدين الدردير، الإعـلام الثوري في ليبيـا: الأسس والأهـداف والمبـادئ

والسياسات، بحلة البحوث الإعلامية، عدد رقم 34-35 تصدر عن مركز البحوث والمعلومات والتوثيق الثقافي والإعلامي، طرابلس، 2007.

4-الشريف عابدين الدردير، السياسة الإعلامية في ليبيا، طرابلس، منشورات أكاديمية

الدراسات العليا، ط1، 2005.

5-الشريف عابدين الدردير، توظيف النظرية في البحتث الإعلامي، طرابلس، شركة

الخبراء المتميزون للخدمات الإعلامية، ط1، 15.

6-عبـدالفتاح علي، الإعـام الدبلوماسي والسياسي، عمـان، دار اليـازوري العلميـة

للنشر والتوزيع، ط1، 1616.

7-القـذافي معمـر، الكتـاب الأخضـر، الصـحافة (حسل مشـكلة الديمقراطيـة) الفصل

الأول، طرابلس، الشركة العامة للنشر والتوزيع والإعلان، 1984.

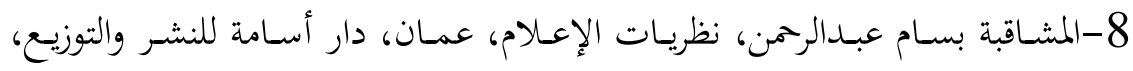

.2014 61

المواقع الإلكترونية:

https://www.youtube.com/watch?v=w7XK9UEsypw

كلمة معمر القذافي الموجه للشعب التونسي بتاريخ 15 يناير 2011.

https://www.youtube.com/watch?v=pfCNfMUgbU4

خطاب القذافي الموجه للشعب اللبي بتاريخ 22 فبراير 2011.

https://www.youtube.com/watch?v=1J_oECAgEto 


$$
\text { خطاب سيف الإسلام القذافي بتاريخ } 21 \text { فبراير } 2011 .
$$

https://www.youtube.com/watch?v=LpGGFIK5YrA الحلقة الأخيرة من برنامج عشم الوطن الذي كان يقدم يوسف شاكير بتاريخ 2011 أغسطس 2011.

/http://lcfp.org.ly/report/hatespeech تقرير خطاب الكراهية في القنوات التلفزيونية الصادر عن المركز الليبي لحرية الصحافة في 16-21 فبراير 2017. https://www.facebook.com/m.jibril.official.page/phot os/a.289061201162689.67926.278685185533624/3635016 50385310/?type=1\&theater كمثال على ذلك انظر الصفحة الرسمية للدكتور محمود جبريل التي نشر فيها برنابحه الانتخابي للمؤتمر الوطني العام 2012. 